\title{
EVALUASI KESELAMATAN OPERASI REAKTOR RSG-GAS SETELAH 33 TAHUN
}

\author{
Pardi Pardi dan Purwadi Purwadi \\ Pusat Reaktor Serbaguna BATAN \\ Kawasan Puspiptek GD 31 Serpong, Tangerang Selatan, Banten \\ Email:pardi@batan.go.id, purwadi14@batan.go.id,
}

\begin{abstract}
ABSTRAK
EVALUASI KESELAMATAN OPERASI REAKTOR RSG-GAS SETELAH 33 TAHUN. Keselamatan operasi reaktor RSG-GAS merupakan faktor utama yang menjadi pertimbangan dalam mengoperasikan reaktor. Keselamatan operasi reaktor harus menjamin bahwa parameter neutronik dan termohidraulik teras RSG-GAS tidak melebihi batas keselamatan operasi (BKO) yang telah ditetapkan di dalam dokumen Safety Analysys Report (SAR). Setelah 33 tahun beroperasi banyak komponen dan sistem teras RSG-GAS yang sudah diganti namun harus dipastikan bahwa parameter operasi tidak ada yang melanggar batas operasi dan batas keselamatan. Evaluasi keselamatan operasi teras RSG-GAS dilakukan dalam rangka penilaian keselamatan periodik yang merupakan persyaratan untuk mendapat izin operasi dari pihak pengawas yaitu Bapeten. Evaluasi atau penilaian keselamatan dilakukan berdasarkan perhitungan dengan menggunakan program komputer dan eksperimen langsung melihat parameter yang terukur pada panel sensor. Perhitungan parameter neutronik dilakukan dengan program WIMSD-5B/Batan-FUEL. Hasil eksperimen dan perhitungan parameter keselamatan operasi teras reaktor RSG-GAS tidak ada yang melampaui batas operasi dan batas keselamatan namun ada yang sudah berubah dari desain. Hal ini disebabkan oleh faktor umur reaktor yang telah beroperasi 33 tahun, namun masih dalam batas rentang operasi dan keselamatan yang ditetapkan.
\end{abstract}

Kata kunci : keselamatan operasi, RSG-GAS, Batan-FUEL, WIMSD-5D, teras kerja .

\section{ABSTRACT}

OPERATION SAFETY EVALUATION OF RSG-GAS REACTOR AFTER 33 YEARS. The safety of the RSG-GAS reactor operation is a major factor being considered in operating the reactor. The safety of the reactor operation must ensure that the RSG-GAS core neutronic and thermohidaulic parameters do not exceed the operational safety limits (OSL) set out in the Safety Analysis Report (SAR) document. After 33 years of operation many of the RSG-GAS core components and systems have been replaced but must be ensured that no operating parameters violate operating and safety limits. RSG-GAS core operation safety evaluation is carried out in the context of periodic safety assessment which is a requirement to obtain an operating license from the supervisor, Bapeten. Safety evaluation or assessment is based on calculations using a computer program and direct experiments see the measured parameters on the sensor panel. Neutronic parameter calculations are performed using the WIMSD-5B / Batan-FUEL program. The results of experiments and calculation of the safety parameters of the RSG-GAS reactor core operation have not exceeded the operational and safety limits, but there have been changes in the design. This is due to the operating age of the reactor which has been operating for 33 years, but is still within the limits of the specified operating and safety range.

Keywords: operational safety, RSG-GAS, Batan-FUEL, WIMSD-5D, working core 


\section{PENDAHULUAN}

RSG-GAS dibangun oleh BATAN dengan tujuan untuk produksi radioisotop, penelitian dan pengujian material nuklir serta sarana latihan bagi operator dalam rangka pembangunan Pembangkit Listrik Tenaga Nuklir (PLTN) di Indonesia. Semua aktivitas selama operasi selalu mengutamakan keselamatan baik dalam pemilihan komponan dan sistem operasi di teras reaktor RSG-GAS. Untuk memberikan feedback kepada operator maka dibutuhkan evaluasi keselamatan operasi. Pada prinsipnya, evaluasi keselamatan operasi harus mendukung kegiatan yang dapat mempengaruhi parameter neutronik dan termohidraulik operasi reaktor [1]. Beberapa kegiatan utama yang melibatkan evaluasi keselamatan operasi teras reaktor RSGGAS yaitu manajemen bahan bakar di dalam teras, mengganti komponen dan sistem reaktor, peningkatan daya, perubahan elemen bakar baru, pengaturan eksperimen, penyimpanan bahan bakar bekas, dan penuaan komponen reaktor. Evaluasi keselamatan operasi reaktor yang terkait dengan tujuan memodifikasi sistem reaktor harus dilakukan dengan mengubah dokumen laporan analisis keselamatan reaktor yang dilakukan oleh lembaga kompeten yang relevan. Namun demikian, karena sifat eksperimental dari penelitian reaktor RSGGAS, kegiatan tertentu yang membutuhkan evaluasi keselamatan harus dilakukan oleh tim operasional sendiri, misalnya modifikasi konfigurasi teras karena eksperimen dan manajemen bahan bakar. Pentingnya parameter keselamatan operasi reaktor adalah untuk menjaga keselamatan dalam desain serta selama operasi reaktor RSGGAS berlangsung. Program komputer banyak digunakan sebagai alat untuk analisis keselamatan dalam kerangka kerja pembaharuan lisensi operasi reaktor dan Penilaian Keselamatan Berkala (PKB). Tujuan dari penelitian ini adalah untuk menjelaskan parameter keamanan paling penting dari Reaktor riset RSG-GAS dari aspek operasional sementara secara bersamaan bertindak sebagai PKB. Parameter keselamatan yang dibahas dalam makalah ini adalah sebagai berikut: distribusi fraksi bakar, faktor daya puncak, margin padam, parameter operasi dan paparan radiasi. Parameter ini ada yang dihitung misalnya fraksi bakar dan faktor puncak daya dan ada yang hasil eksperimen dan pengukuran. Perhitungan dilakukan dengan menggunakan program komputer dan paket terintegrasi yang disesuaikan dengan kebutuhan praktis dalam manajemen bahan bakar teras, yaitu WIMSD-5B dan BATAN-FUEL. Kode WIMSD-5B [2] digunakan untuk menghasilkan $\mathrm{x}$-section dari bahan bakar teras RSG-GAS, sedangkan kode BATAN-FUEL [3] digunakan dalam menghitung parameter teras. Program komputer ini digunakan 
untuk menghitung parameter neutronik untuk keselamatan operasi dan diverifikasi menggunakan data desain teras RSG-GAS [4].

\section{METODOLOGI PENELITIAN}

Penelitian ini dilakukan dengan cara mengumpulkan data operasi reaktor, data gangguan, insiden, perawatan reaktor, pemrosesan data dan evaluasi parameter keselamatan operasi reaktor RSG-GAS. Kegiatan pengumpulan data dilakukan untuk desain, data parameter operasi termasuk data gangguan, insiden dan kecelakaan reaktor dari laporan operasi reaktor [5].

\section{Data eksperimental}

Shutdown Margin (SDM) adalah jumlah reaktivitas yang tersedia, di mana reaktor menjadi keadaan subkritis jika semua batang kendali dimasukkan ke teras reaktor sepenuhnya. Jika satu batang kendali dengan nilai reaktivitas terbesar, yang diasumsikan sepenuhnya ditarik atau macet, batang kendali lainnya harus memiliki reaktivitas negatif untuk membuat reaktor dalam keadaan subkritis. Reaktivitas shutdown margin reaktor sangat penting ditentukan secara eksperimental; biasanya sekitar 1-5\% disediakan untuk tujuan keselamatan. Namun, kriteria batang terjebak macet mengacu pada fakta bahwa, margin shut-down reaktivitas harus tersedia meskipun satu batang kendali macet tidak dapat memasuki teras reaktor. Menerapkan kriteria batang terjebak untuk memastikan kegagalan batang kendali tunggal dan tidak akan mencegah sistem batang kendali dari mematikan reaktor. Untuk itu diperlukan margin shut-down operasi reaktor. Reaktor dapat berupa kondisi subkritis atau aman saat batang kendali macet terjadi. Subkritikalitas dengan $\mathrm{k}_{\mathrm{eff}}=0,99$ dengan semua batang kendali dimasukkan ke teras reaktor bukanlah kondisi subkritis yang aman [6]. Reaktor riset RSG-GAS (MPR-30) beroperasi pada 15 MWt. Untuk setiap siklus sebelum percobaan kekritisan (awal siklus), itu dilakukan perhitungan kekritisan dengan tujuan (1) untuk teras kerja dan untuk menentukan batang kendali yang memiliki nilai reaktivitas terbesar (2) untuk kondisi One-Stuck-Rod (OSR). Kondisi OSR disimulasikan dengan menarik batang kendali dan kemudian dijatuhkan secara bebas ke dalam teras namun 1 batang kndali gagal masuk ke dalam teras. RSG-GAS memiliki 8 batang kendali, maka dilakukan perhitungan kritikalitas yang berbeda. Dalam kondisi OSR, dihitung faktor multiplikasi neutron ( $\mathrm{k}_{\mathrm{eff}}$ ) hasilnya harus lebih rendah dari 0,98 , atau paling tidak $1 \%$ shut-down margin untuk OSR. Jika dimasukkan untuk semua batang kendali $\mathrm{k}_{\text {eff }}$ harus jauh lebih kecil dari 0,98. Hal ini untuk mengatur margin shut-down untuk OSR setidaknya $1 \%$ karena regulasi menetapkan demikian dan juga 
mempertimbangkan keakuratan alat ukur yang digunakan. Teras reaktor GAS-RSG tidak menggunakan racun yang bisa dibakar, kondisi OSR diukur pada awal teras (BOC), Kondisi OSR ini selalu diperiksa Panitia Keselamatan [7].

\section{Perhitungan sel}

Untuk memecahkan persamaan kinetika neutron, data penampang lintang makroskopik untuk berbagai bahan dalam inti telah diatur. Untuk untuk tujuan ini, digunakan program WIMSD-5B. Program ini mengidentifikasi sel-sel material sebagai pembentuk teras reaktor. Hal yang perlu dipertimbangkan saat mendefinisikan dimensi sel satuan, prinsip-prinsip konservasi rasio volume pada meterial yang berbeda dalam perakitan bahan bakar. Perakitan bahan bakar dalam konfigurasi teras RSG-GAS ditunjukkan pada Gambar 1.

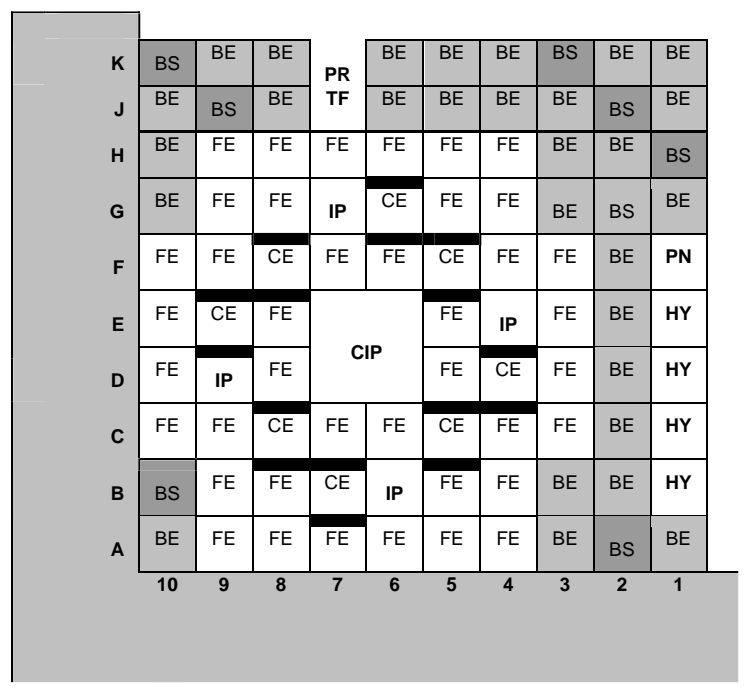

Gambar 1. Konfigurasi teras RSG-GAS [8]
Dimensi sel bahan bakar dihitung dengan memperlakukan konservasi bahan bakar uranium silisida. Model sel unit bahan bakar untuk elemen bahan bakar RSG-GAS ditunjukkan pada Gambar 2.

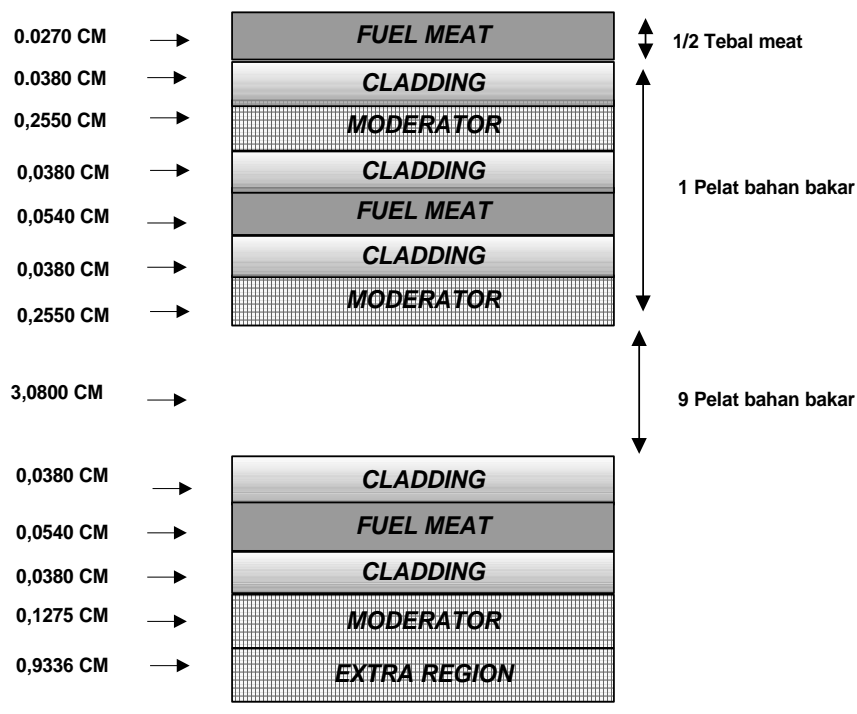

Gambar 2. Model sel elemen bakar teras RSG-GAS[9]

Dengan menambahkan ekstra wilayah untuk sisa air dan aluminium dalam proporsi yang sama seperti pada elemen bahan bakar fisik, wilayah ini termasuk aluminium di pinggir luar lebar daging dan pelat samping aluminium air di luar lebar daging, dan saluran air yang mengelilingi elemen bahan bakar). Dalam kasus khusus elemen kendali, itu menggunakan opsi super sel dari WIMSD-5B[10], dengan memodelkan sel representatif 15 daerah. Pemodelan batang kendali dan kotak kontrol absorber serupa dengan pemodelan bahan bakar. Dimensi bahan bakar 2-D ditunjukkan pada Gambar 3. 


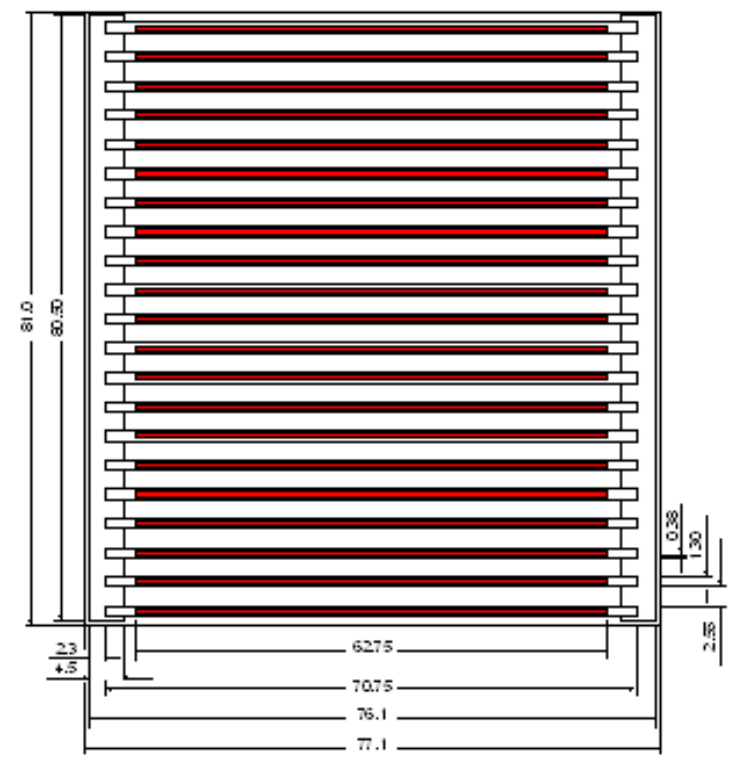

Gambar 3. Bahan bakar teras RSG-GAS[11]

Program WIMSD-5B menghasilkan data penampang makroskopik sebagai fungsi burn-up bahan bakar dan suhu moderator. Perbedaan nilai pembakaran mulai dari $0 \%$ hingga 90\% dianggap menghasilkan semua kondisi, mulai dari awal siklus, dan akhir dari siklus [12]. Suhu bahan bakar dan moderator mencakup kondisi teras secara keseluruhan untuk kondisi operasi normal dan kondisi tertentu. Makroskopis crosssection dibuat untuk menentukan kecepatan rata-rata neutron. Ini menghasilkan penampang dalam 4 kelompok energi neutron, tetapi saat menentukan kecepatan rata-rata neutron, dilakukan pada energi 69 kelompok neutron. Ini menggunakan kecepatan rata-rata neutron dalam 4 kelompok kekuatan yang dihitung berdasarkan bobot kecepatan neutron dalam 69 kelompok energi dengan fluks sel ratarata [13]. Konstanta tampang lintang makroskopik dihitung oleh paket program WIMSD-5B dalam 4 kelompok energi neutron, batas-batas energi neutron setiap kelompok yang dipilih adalah $10 \mathrm{MeV}$, 0,821 MeV, 5,531 keV, 0,625 eV dan $1 \times 10$ 5 eV [14]. Khusus untuk bahan bakar pembangkitan konstanta kelompok yang dibangkitkan sebagai fungsi massa ${ }^{235} \mathrm{U}$ dalam perangkat (250 gram), temperatur (dingin dan panas) dan kondisi Xe free dan setimbang. Konstanta kelompok difusi neutron sebagai fungsi temperatur dan densitas yang sesuai dengan fraksi bakar teras diperoleh dengan cara interpolasi. Dengan menggunakan konstanta tampang lintang yang telah diinterpolasi dilakukan perhitungan teras dengan fraksi bakar tertentu. Tahapan dalam perhitungan sel adalah sebagai berikut [15]:

a. X-section makroskopik sebagai fungsi dari burn-up dihasilkan pada energi neutron 4 kelompok kondisi suhu $20^{\circ} \mathrm{C}$.

b. X-section makroskopik untuk bahan bakar elemen dihasilkan sebagai fungsi dari suhu $20^{\circ} \mathrm{C}$.

c. X-section makroskopik untuk moderator dihasilkan sebagai fungsi dari suhu $20^{\circ} \mathrm{C}$. Pada tahap ini, tidak ada perubahan densitas moderator, demikian juga material non-fisi lainnya.

\section{Perhitungan Teras}

Prosedur desain neutronik ditunjukkan dalam diagram skematik Gambar 4. 


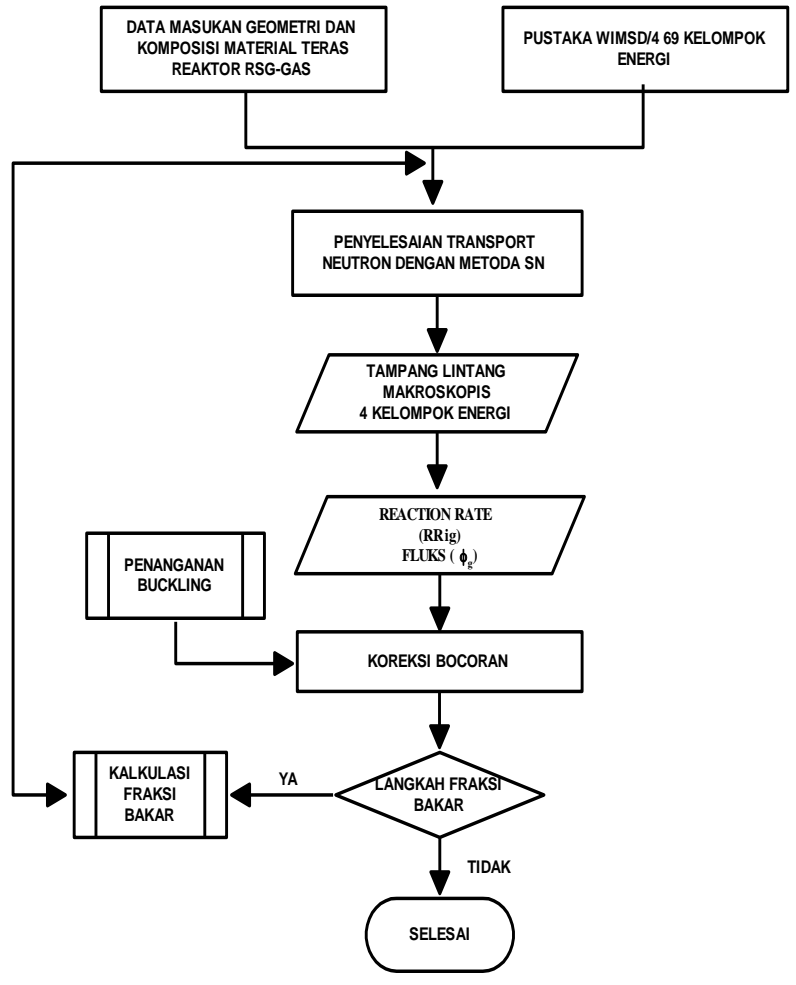

Gambar 4. Diagram alir perhitungan WIMSD$5 \mathrm{~B}[16]$

Pertama, pustaka tampang lintang untuk fisil dan bahan non-fisil disiapkan dengan program perhitungan sel WIMSD5B. Pusta data nuklir disiapkan untuk mengakomodasi rentang luas parameter desain seperti tingkat pembakaran bahan bakar, kerapatan daging bahan bakar, suhu operasional bahan bakar, dan keberadaan racun neutron (xenon dan samarium). Data reaktor pada umumnya adalah pengisian bahan bakar, strategi penempatan bahan bakar, dan panjang siklus teras dimasukkan ke dalam input program perhitungan khusus modul manajemen, Batan-EQUIL2D [17]. Fungsi utama program BatanEQUIL-2D adalah untuk langsung mencari keseimbangan teras tanpa mensimulasikan teras transisi. Karena program tersebut menggunakan teori difusi 2-D, sebuah buckling aksial yang akurat harus disediakan melalui perhitungan difusi 3-D yang akurat oleh modul Batan-3DIFF. Konfigurasi teras setimbang yang telah ditentukan dengan Batan-3DIFF maka perhitugan dilanjutkan dengan menentukan panjang siklus, kemudian dilakukan pengecekan untuk mengetahui apakah reaktivitas lebih pada akhir siklus (EOC) di bawah kondisi kesetimbangan panas dan xenon adalah cukup aman. Jika panjang siklus teras awalnya ditentukan tidak tepat, maka penyesuaian harus dilakukan untuk memberikan nilai parameter neutronik pada kondisi EOC yang cukup [15]. Kemudian dilakukan perhitungan dalam teori difusi 2D dengan Modul Batan-2DIFF ditunjukkan Gambar 5.

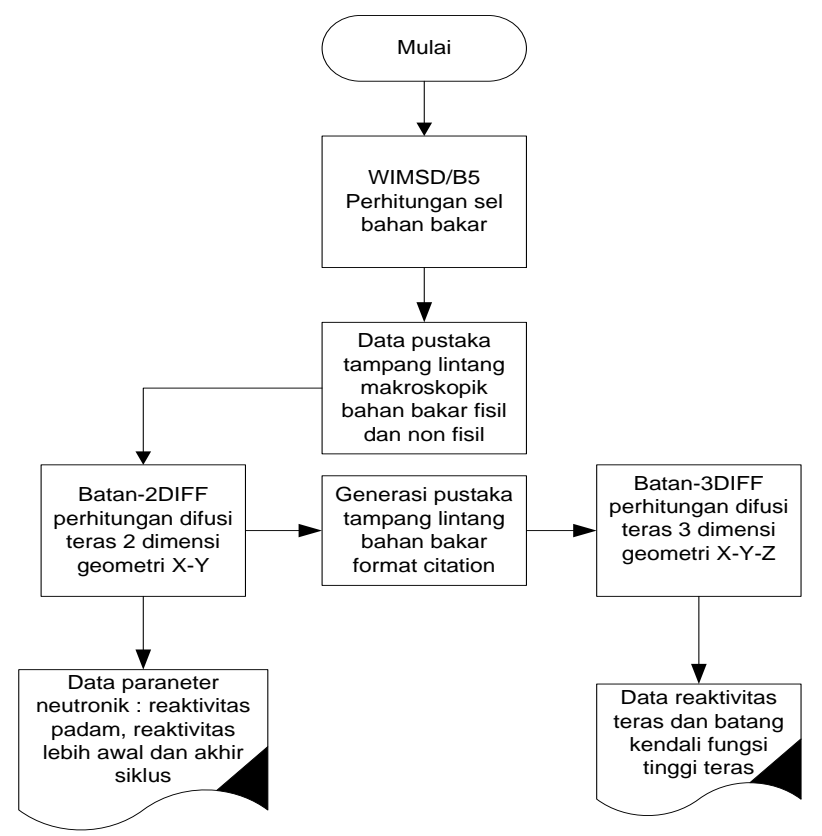

Gambar 5. Diagram alir perhitungan BatanFUEL[18] 
Untuk menentukan kondisi subkritis onestuck-rod dilakukan dngan program Batan3DIFF. Jika tidak memenuhi persyaratan keamanan, maka modifikasi pada pengaturan Fuel Element (FE) seharusnya dilakukan di seluruh teras atau bahkan dilakukan penambahan atu pengurangan jumlah bahan bakar dan strategi penempatan bahan bakar semua dilakukan perubahan. Penyesuaian juga diperlukan untuk mendapatkan distribusi daya yang merata secara aksial teras reaktor untuk menjamin bahwa kondisi elemen bakar masih dalam kondisi baik [16]. Ada beberapa bahan bakar yang terlihat bercak putih atau hitam namun karena tidak terlihat adanya deformasi fisik pada bagian bercak putih atau hitam tersebut permukaan plat terlihat halus maka masih dikategorikan baik.

\section{HASIL DAN PEMBAHASAN}

Data operasi teras kerja RSG-GAS meliputi jumlah energi yang dibangkitkan, jumlah ${ }^{235} \mathrm{U}$, burn-up awal dan akhir siklus. Seperti yang ditunjukkan pada Tabel 1 . Posisi batang kendali kritis awal, dingin tanpa xenon $275 \mathrm{~mm}$. Dari posisi awal kritis batang kendali jika dibandingkan setelah 33 tahun operasi sudah berbeda. Hal ini karena berilium blok dan reflektor sudah meluruh. Posisi batang kendali awal siklus all bank pada daya 15 MW $286 \mathrm{~mm}$ dan pada akhir siklus bank $541 \mathrm{~mm}$ dan RR $546 \mathrm{~mm}$.

Energi yang dibangkitkan 640,5971 MWD selama 42 hari operasi dengan 1.042,78 jam daya 15 MW. Daya yang dioperasikan 15 MW sesuai dengan kebutuhan operasi, namun jika dibutuhkan tidak tertutup kemungkinan RSG-GAS dapat dioperasikan dengan daya $30 \mathrm{MW}$. 
Tabel 1. Parameter neutronik teras RSG-GAS

\begin{tabular}{clll}
\hline No & \multicolumn{1}{c}{ Parameter } & \multicolumn{2}{c}{ Data Total } \\
\hline 1 & Bahan Bakar & Awal & Akhir \\
& Jumlah gram ${ }^{235} \mathrm{U}$ dalam teras & $8.671,4$ gram & $7.939,8$ gram \\
& Fraksi Bakar Rerata & $23,81 \%$ & $30,24 \%$ \\
& Posisi batang kendali $15 \mathrm{MW}$ & Bank $: 286 \mathrm{~mm}$ & Bank $: 541 \mathrm{~mm}$ \\
& & Regulating Rod :286 mm Regulating Rod :546 mm \\
2 & Posisi Batang Kendali Bebas & Bank :275 mm & Jumlah energi 640,5971 \\
& Sumber & Regulating Rod :275 mm & MWD \\
\hline
\end{tabular}

Tabel 2. Nilai reaktivitas batang kendali

\begin{tabular}{clcc}
\hline No & Posisi batang kendali & $(\%)$ & $(\$)$ \\
\hline 1 & JDA 01 + 15, Posisi E-9 & 1,570 & 2,052 \\
2 & JDA 02 + 12, Posisi G-6 & 1,610 & 2,105 \\
3 & JDA 03 + 10, Posisi F-8 & 1,817 & 2,375 \\
4 & JDA 04 + 13, Posisi F-5 & 1,756 & 2,295 \\
5 & JDA 05 + 16, Posisi C-5 & 1,809 & 2,365 \\
6 & JDA 06 + 11, Posisi C-8 & 1,408 & 1,835 \\
7 & JDA 08 + 14, Posisi B-7 & 1,377 & 1,800 \\
8 & REGROD+ 09, Posisi D-4 & 1,851 & 2,419 \\
9 & Reaktivitas Total Batang Kendali & $-13,200$ & $-17,255$ \\
10 & Reaktivitas Padam & $-6,200$ & $-8,105$ \\
11 & Reaktivitas Lebih Teras 99 Awal & 7,000 & 9,150 \\
12 & Reaktivitas pada kondisi stuck rod & $-4,340$ & $-5,673$ \\
13 & Reaktivitas batang kendali terbesar & $-1,850$ & $-2,418$ \\
& (JDA 04 posisi F-5) & &
\end{tabular}

Neraca reaktivitas dan posisi batang kendali dapat dilihat dalam Tabel 2. Dari hasil pengukuran kalibrasi batang kendali awal siklus (BOC) teras RSG-GAS dapat diketahui neraca reaktivitas teras sedangkan susunan bahan bakar dalam teras yang optimum untuk mencapai kritikalitas dapat dilihat pada Gambar 3 menunjukkan bahwa core terdiri 40 bahan bakar dan 8 batang kendali. Setiap akhir siklus dikeluarkan 5 bahan bakar dan 1 bahan bakar kendali yang mempunyai reaktivitas terbesar. Reaktivitas batang kendali total hasil pengukuran untuk teras RSG-GAS ternyata ada perbedaan dengan nilai reaktivitas batang kendali total, reaktivitas lebih dan reaktivitas stuck rod dengan desain awal. Reaktivitas total batang kendali desain $14,2 \%$ dan reaktivitas lebihnya 
9,2\%. Setelah beroperasi 33 tahun nilai reaktivitas batang kendali total 13,2 \% dan reaktivitas lebihnya $7,0 \%$. Nilai reaktivitas lebih yang tersedia masih cukup untuk kebutuhan iradiasi sampel di teras RSG-GAS. Namun nilai ini tidak hanya karena penurunan kualitas bahan reaktor seperti berilium blok dan reflektor tapi juga oleh karena manajemen bahan bakar yang digunakan di teras RSGGAS saat ini. Namun yang paling penting adalah batas keselamatan operasi masih diizinkan karena harga reaktivitas batang kendali masih mampu untuk mengontrol reaktivitas lebihnya dan pada kondisi stuck rod reaktivitas padamnya - $0,5 \%$ sesuai dengan nilai desainnya. Nilai reaktivitas individu batang kendali berbeda untuk 8 batang kendali namun masih dianggap merata. Perbedaan harga reaktivitas batang kendali ini dikarenakan kondisi burn up di posisi batang kendali di teras yang digunakan berbeda dalam pengukuran. Ketika pengukuran dilakukan kondisi teras sudah beroperasi 33 tahun dimana kompenen teras sudah terdegradasi. Sementara pada perhitungan dilakukan kompenen teras seperti berelium blok dan reflektor dimodelkan pada kondisi baru. Perbedaan ini juga dapat disebabkan oleh karena derajat bakar bahan bakarnya berbeda setiap posisi. Semakin lama bahan bakar di dalam teras maka fraksi bakarnya semakin bertambah besar karena jumlah uraniumnya berkurang karena deflesi.

Hasil perhitungan burn-up tiap elemen bakar pada akhir periode T-98 menggunakan program yang sudah tervalidasi yaitu program WIMSD5B/Batan-FUEL dapat dilihat dalam Tabel 3. Tabel 3 menunjukkan bahwa dari aspek keselamatan reaktivitas, pengendalian reaktivitas pada teras RSG-GAS dapat diterima. karena tidak ada yang melanggar batas keselamatan dimana kondisi stuck rod $>-0,5 \% \Delta \mathrm{k} / \mathrm{k}$ dan FPD $<1,4$ dan fluks neutron sudah memenuhi persyaratan yaitu lebih besar dari $1,25 \times 10^{14} \mathrm{n} / \mathrm{cm}^{2} \mathrm{~s}$ pada daya 15 MW. Hal yang perlu diperhatikan adalah reaktivitas teras kondisi stuck rod untuk teras dengan muatan $250 \mathrm{~g}$ adalah $-0,51$ $\% \Delta \mathrm{k} / \mathrm{k}$, berarti margin padam melebihi syarat batas keselamatan. 
Tabel 3. Hasil perhitungan nilai burn-up bahan bakar Uranium Silisida

\begin{tabular}{|c|c|c|c|c|c|c|c|c|}
\hline \multirow[b]{2}{*}{ No } & \multirow{2}{*}{$\begin{array}{l}\text { Kode Elemen } \\
\text { Bakar }\end{array}$} & \multirow{2}{*}{$\begin{array}{l}\text { Posisi di } \\
\text { Teras }\end{array}$} & \multirow{2}{*}{$\begin{array}{c}\text { PPF } \\
\text { (Max. } \\
1,23 \text { ) }\end{array}$} & \multicolumn{2}{|c|}{ Fraksi Bakar } & \multicolumn{2}{|c|}{ Berat ${ }^{235} \mathrm{U}$ (gram) } & \multirow[b]{2}{*}{ Massa awal } \\
\hline & & & & $\%$ & MWD/THM & Sisa & Terbakar & \\
\hline 1 & RI-625 & A-9 & 1,0374 & 6,392 & $10.252,000$ & 233,355 & 15,935 & 249,29 \\
\hline 2 & RI-624 & $\mathrm{H}-4$ & 0,9813 & 6,663 & $10.690,600$ & 232,547 & 16,513 & 249,06 \\
\hline 3 & RI-628 & H-9 & 0,9258 & 6,851 & $10.994,500$ & 231,932 & 17,058 & 248,99 \\
\hline 4 & RI-627 & F-3 & 0,9436 & 7,098 & $11.393,900$ & 231,521 & 17,689 & 249,21 \\
\hline 5 & RI-626 & $\mathrm{C}-3$ & 0,8476 & 7,338 & 11.781 .300 & 230,497 & 18,253 & 248,75 \\
\hline 6 & RI-581 & B-8 & 0,9993 & 49,861 & $83.938,500$ & 124,475 & 123,785 & 248,26 \\
\hline 7 & RI-620 & A-4 & 1,0708 & 12,820 & $20.698,700$ & 216,808 & 31,882 & 248,69 \\
\hline 8 & RI-621 & $\mathrm{H}-8$ & 0,8909 & 13,722 & $22.275,700$ & 241,253 & 34,667 & 248,92 \\
\hline 9 & RI-622 & $\mathrm{C}-10$ & 0,9526 & 13,927 & $22.571,700$ & 241,339 & 34,681 & 249,02 \\
\hline 10 & RI-623 & F-10 & 0,8499 & 14,253 & $23.045,600$ & 241,051 & 35,579 & 249,63 \\
\hline 11 & RI-619 & F-9 & 0,8794 & 14,369 & $23,236,500$ & 231,735 & 35,865 & 249,60 \\
\hline 12 & RI-629 & F-5 & 1,1327 & 16,195 & $26.240,300$ & 200,052 & 49,398 & 249,45 \\
\hline 13 & RI-614 & E-10 & 1,1750 & 19,777 & $32.165,500$ & 199,595 & 49,205 & 248,80 \\
\hline 14 & RI-613 & A-5 & 1,1867 & 20,579 & $33.497,700$ & 197,806 & 51,254 & 249,06 \\
\hline 15 & RI-616 & E-3 & 1,1072 & 20,731 & $33.750,400$ & 197,721 & 51,709 & 249,43 \\
\hline 16 & RI-615 & C-4 & 0,9296 & 20,878 & $33.994,500$ & 197,180 & 52,030 & 249,21 \\
\hline 17 & RI-618 & G-9 & 1,2001 & 21,163 & $34.468,700$ & 196,738 & 52,812 & 249,55 \\
\hline 18 & RI-582 & D-8 & 0,9608 & 49,965 & $84.125,100$ & 124,172 & 123,998 & 248,17 \\
\hline 19 & RI-606 & B-4 & 1,0680 & 26,166 & $42.846,100$ & 183,222 & 66,478 & 249,70 \\
\hline 20 & RI-605 & H-6 & 1,0711 & 26,623 & $43.615,500$ & 183,024 & 66,406 & 249,43 \\
\hline 21 & RI-608 & A-7 & 1,0206 & 26,947 & $44.162,500$ & 182,187 & 67,203 & 249,39 \\
\hline 22 & RI-607 & D-5 & 1,1823 & 28,504 & $46.792,100$ & 178,015 & 71,015 & 249,14 \\
\hline 23 & RI-609 & E-8 & 1,1044 & 28,887 & $47.441,700$ & 177,285 & 72,015 & 249,30 \\
\hline 24 & RI-586 & B-5 & 0,9579 & 51,252 & $86.435,400$ & 120,676 & 126,874 & 247,55 \\
\hline 25 & RI-601 & A- 6 & 0,9957 & 32,349 & $53.330,800$ & 169,127 & 80,873 & 250,00 \\
\hline 26 & RI-603 & $\mathrm{H}-7$ & 1,0048 & 32,784 & $54.073,200$ & 167,932 & 81.908 & 249,84 \\
\hline 27 & RI-600 & D-10 & 1,1679 & 32,970 & $54.391,900$ & 166,972 & 82,128 & 249,10 \\
\hline 28 & RI-602 & H-5 & 1,0789 & 33,821 & $55.848,700$ & 165,222 & 84,438 & 249,66 \\
\hline 29 & RI-604 & D-3 & 0,9033 & 34,571 & $57.135,500$ & 163,422 & 86,348 & 249,77 \\
\hline 30 & RI-596 & B-9 & 1,0385 & 37,923 & $62.915,500$ & 153,343 & 93,677 & 247,02 \\
\hline 31 & RI-588 & G-8 & 0,9563 & 52,411 & $88.527,700$ & 118,025 & 129,985 & 248,01 \\
\hline 32 & RI-595 & G-4 & 1,2258 & 38,663 & $64.199,400$ & 151,827 & 95,703 & 247,53 \\
\hline 33 & RI-598 & F-6 & 0,9824 & 39,888 & $66.331,000$ & 150,064 & 99,576 & 249,64 \\
\hline 34 & RI-597 & E-5 & 1,0735 & 40,956 & $68.192,100$ & 147,049 & 102,001 & 249,05 \\
\hline 35 & RI-599 & C-6 & 1,1094 & 41,424 & $69.012,500$ & 146,540 & 103,630 & 250,17 \\
\hline 36 & RI-590 & C-9 & 1,1013 & 43,533 & $72.706,400$ & 139,846 & 107,814 & 247,66 \\
\hline 37 & RI-589 & $\mathrm{C}-7$ & 0,8513 & 44,853 & $75.031,000$ & 136,505 & 111,025 & 247,53 \\
\hline 38 & RI-592 & A-8 & 0,8023 & 45,609 & $76.367,100$ & 134,656 & 112,914 & 247,57 \\
\hline 49 & RI-593 & F-4 & 0,8748 & 45,643 & $76.428,000$ & 134,828 & 113,212 & 248,04 \\
\hline 40 & RI-594 & G-5 & 0,8860 & 46,870 & $78.601,300$ & 131,444 & 115,956 & 247,40 \\
\hline
\end{tabular}


Tabel 4. Hasil perhitungan nilai burn-up di posisi batang kendali

\begin{tabular}{|c|c|c|c|c|c|c|c|c|}
\hline \multirow[b]{2}{*}{ No } & \multirow{2}{*}{$\begin{array}{c}\text { Kode Elemen } \\
\text { Bakar }\end{array}$} & \multirow{2}{*}{$\begin{array}{l}\text { Posisi di } \\
\text { Teras }\end{array}$} & \multirow{2}{*}{$\begin{array}{c}\text { PPF } \\
\text { (Max. } \\
1,23)\end{array}$} & \multicolumn{2}{|c|}{ Fraksi Bakar } & \multicolumn{2}{|c|}{ Berat ${ }^{235} \mathrm{U}$ (gram) } & \multirow[b]{2}{*}{ Massa awal } \\
\hline & & & & $\%$ & MWD/THM & Sisa & Terbakar & \\
\hline 1 & RI-591 & G-6 & 0,7419 & 50,422 & $84.943,200$ & 87,758 & 89,252 & 177,01 \\
\hline 2 & RI-587 & F-5 & 0,9657 & 51,559 & $86.988,600$ & 86,061 & 91,599 & 177,66 \\
\hline 3 & RI-585 & B-7 & 0,9780 & 55,965 & $94.996,000$ & 85,104 & 92,266 & 177,37 \\
\hline 4 & RI-610 & E-9 & 1,1030 & 44,447 & $74.317,200$ & 98,757 & 79,013 & 177,77 \\
\hline 5 & RI-611 & D-4 & 0,9079 & 37,985 & $63.024,700$ & 110,287 & 67,553 & 177,84 \\
\hline 6 & RI-612 & C-5 & 1,0475 & 31,082 & $51.168,900$ & 122,605 & 55,295 & 177,90 \\
\hline 7 & RI-630 & $\mathrm{C}-8$ & 1,0052 & 8,259 & $13.271,900$ & 162,666 & 14,644 & 177,31 \\
\hline 8 & RI-617 & F-8 & 0,9091 & 23,927 & $39.085,400$ & 135,516 & 42,624 & 178,14 \\
\hline
\end{tabular}

diposisi batang kendali dapat dilihat pada Tabel 4. Jumlah ${ }^{235} \mathrm{U}$ di bahan bakar di posisi batang kendali tidak sama dengan bahan bakar. Jumlah massa uraniumnya dapat dilihat pada Tabel 4. Burn up terbesar hasil perhitungan terdapat pada posisi B-7 yaitu 55,96 \%, namun masih jauh dari nilai maksimum discharged burn up yaitu 59,99\% (SAR RSG-GAS). Material batang kendali yang selama 33 tahun sudah mengalami penggantian $1 \mathrm{x}$ setelah 40 siklus operasi atau 30.000 MWD operasi.

Target yang diiradiasi pada pengoperasian reaktor RSG-GAS ini cukup beragam. Di fasilitas Central Iradiation Position (CIP) terdapat $\mathrm{Sm}_{2} \mathrm{O}_{3}, \mathrm{Lu}_{2} \mathrm{O}_{3}, \mathrm{MoO}_{3}$, $\mathrm{TeO}_{2}, \mathrm{Gd}_{2} \mathrm{O}_{3}, \mathrm{Yb}_{2} \mathrm{O}_{3}$, Sulfur, Al-6061 T6. Di beam tube S2 terdapat polietilen, hip, lutut kalibrasi, mesin standstone standar dan material Stainless Steel. Fasilitas beam tube S3 belum dimanfaatkan. Di beam tube S4 terdapat $\mathrm{Si}, \mathrm{TiO}_{2}, \mathrm{Ge}$. Di beam tube S5 terdapat $\mathrm{TiO}_{2}, \mathrm{Ni}, \mathrm{Si}, \mathrm{Al}, \mathrm{Ca}, \mathrm{ZrFe}_{3} \mathrm{O}_{4}$, Zircaloy, $\mathrm{BiFeO}_{4}$ Quartz, $\mathrm{BiFeO}_{3}$ Quartz, $\mathrm{Al}$ Alloy, Al Culsia, Zn Alloy, $\mathrm{TeO}_{2}, \mathrm{LiC}_{3} \mathrm{O}_{2}$ dan material Stainless Steel. Di beam tube S6 terdapat $\mathrm{TiO}_{2}, \mathrm{Ge}$, Besi, material Stainless Steel. Di sistem rabbit terdapat Au-foil, Pasir, SRM-1,2,3, lingkungan biologi, AuAl, $\mathrm{Sm}_{2} \mathrm{O}_{3}$, dan di fasilitas Power Rump Test Facility (PRTF) terdapat pin bahan uji bahan bakar. Sementara semua fasilitas iradiasi yang ada di RSG-GAS, neutron scattering mendominasi utilisasi fasilitas iradiasi dan sebagai pengguna adalah PSTBM. 
Tabel 5. Laju Paparan Radiasi

\begin{tabular}{|c|c|c|c|c|c|c|}
\hline \multirow{3}{*}{ No } & \multirow{3}{*}{$\begin{array}{l}\text { Lokasi } \\
\text { Pengukuran }\end{array}$} & \multirow{3}{*}{$\begin{array}{l}\text { Batas } \\
\text { Maksimum } \\
(\mu \mathrm{Sv} / \mathrm{jam})\end{array}$} & \multicolumn{4}{|c|}{ Laju Paparan $(\mu \mathrm{Sv} / \mathrm{jam})$} \\
\hline & & & \multicolumn{2}{|c|}{ Tidak Operasi } & \multicolumn{2}{|c|}{ Operasi $15 \mathrm{MW}$} \\
\hline & & & Rerata & Maks & Rerata & Maks \\
\hline \multicolumn{7}{|c|}{ Laju Dosis Gamma } \\
\hline 1. & $\begin{array}{ll}\text { Diatas } & \text { Permukaan } \\
\text { Kolam } & \end{array}$ & $1,25 \times 10^{3}$ & 2,51 & $6,00 \times 10^{0}$ & $1,09 \times 10^{1}$ & $2,20 \times 10^{1}$ \\
\hline 2. & Lantai $13,00 \mathrm{~m}$ & $1,25 \times 10^{3}$ & 2,35 & $6,80 \times 10^{0}$ & $7,07 \times 10^{0}$ & $2,20 \times 10^{1}$ \\
\hline 3. & Lantai $8,00 \mathrm{~m}$ & $1,25 \times 10^{3}$ & 3,88 & $1,40 \times 10^{1}$ & $1,20 \times 10^{1}$ & $5,60 \times 10^{1}$ \\
\hline 4. & Lantai $0,00 \mathrm{~m}$ & $1,25 \times 10^{3}$ & 3,35 & $1,60 \times 10^{1}$ & $1,37 \times 10^{1}$ & $5,20 \times 10^{1}$ \\
\hline 5. & Lantai $-6,50 \mathrm{~m}$ & $2,50 \times 10^{1}$ & 2,05 & $8,40 \times 10^{0}$ & $3,63 \times 10^{0}$ & $1,20 \times 10^{1}$ \\
\hline \multicolumn{7}{|c|}{ Laju Dosis Neutron } \\
\hline 1. & Lantai $0,00 \mathrm{~m}$ & $2,50 \times 10^{1}$ & - & - & $2,62 \times 10^{-2}$ & $1,60 \times 10^{-1}$ \\
\hline
\end{tabular}

Pengendalian lingkungan terhadap bahaya kontaminasi radioaktif secara awal dapat dilakukan dengan mendesain gedung, ruangan atau fasilitas fisik, pemantauan kontaminasi, dan dekontaminasi. Desain gedung, ruangan atau fasilitas fisik harus mempertimbangkan potensi terjadinya kontaminasi, oleh karena itu harus dilakukan pembagian daerah kerja. Permukaan tempat kerja, lantai, dinding harus mudah didekontaminasi. Selain itu sistem ventilasi, sanitasi dan fasilitas pendukung seperti penyimpanan limbah radioaktif, fasilitas penyimpanan zat radioaktif, ruang ganti, dan shower harus disesuaikan dengan persyaratan fasilitas atau laboratorium. Pemantauan kontaminasi dilakukan untuk memastikan tingkat kontaminasi tidak melebihi ketentuan yang sudah ditetapkan. Pemantauan kontaminasi dapat dilakukan dengan 2 (dua) metode, yaitu metode langsung dan tidak langsung.

Pemantauan secara langsung dapat diterapkan dalam medan radiasi rendah, biasanya untuk mengetahui kontaminasi permukaan bahan, pakaian, dan kulit.

Pemantauan secara tidak langsung dengan cara uji usap diterapkan apabila laju dosis latar belakang tinggi, akan mengidentifikasi kontaminasi radioaktif secara akurat, geometri pengukuran tidak cocok, memantau kontaminasi beta energi rendah dan permukaan yang akan dipantau tidak dapat diakses dengan probe pemantau kontaminasi. Dekontaminasi cara fisika dapat dilakukan dengan proses pencucian, penyemprotan, pengerokan dan pengelupasan. Dekontaminasi secara kimia dapat dilakukan dengan proses kimia antara lain pengendapan dan pelarutan. Dalam setiap kegiatan, Petugas Proteksi Radiasi (PPR) melakukan pengukuran paparan radiasi gamma pada titik-titik lokasi tertentu serta ruangan-ruangan yang berpotensi tingkat radiasi tinggi, Laju paparan radiasi ini dapat dilihat dalam Tabel 5 dan Tabel 6 . Dari hasil pemantauan daerah kerja tidak 
ada paparan radiasi yang melebihi batas yang ditetapkan.

Tabel 6. Radioaktivitas Udara

\begin{tabular}{|c|c|c|c|c|c|c|}
\hline \multirow{3}{*}{ No } & \multirow{3}{*}{ Lokasi Pengukuran } & \multirow{3}{*}{$\begin{array}{l}\text { Batas } \\
\text { Maksimu } \\
\text { m (Bq/L) }\end{array}$} & \multicolumn{4}{|c|}{ Hasil pengukuran $(\mathrm{Bq} / \mathrm{L})$} \\
\hline & & & \multicolumn{2}{|c|}{ Tidak Operasi } & \multicolumn{2}{|c|}{ Operasi $15 \mathrm{MW}$} \\
\hline & & & Rerata & Maks & Rerata & Maks \\
\hline \multicolumn{7}{|c|}{$\alpha-\beta$ Aerosol } \\
\hline 1 & $\begin{array}{l}\text { Lantai } 13,00 \mathrm{~m} \\
\text { (KLK 01 CR 002) }\end{array}$ & $\begin{array}{l}\alpha \\
7,03 \times 10^{-1}\end{array}$ & $7,26 \times 10^{-4}$ & $3,42 \times 10^{-3}$ & $8,16 \times 10^{-4}$ & $5.12 \times 10^{-3}$ \\
\hline 2 & $\begin{array}{l}\text { Lantai } 13,00 \mathrm{~m} \\
(\text { KLK 01 CR 001) }\end{array}$ & $\begin{array}{l}\beta \\
7,03 \times 10^{-1}\end{array}$ & $8,21 \times 10^{-5}$ & $6,24 \times 10^{-4}$ & $8.87 \times 10^{-5}$ & $7,24 \times 10^{-4}$ \\
\hline 3 & $\begin{array}{l}\text { Lantai } 8,00 \mathrm{~m} \text { dan } 13,00 \mathrm{~m} \\
\text { (KLK 04 CR 002) }\end{array}$ & $\begin{array}{l}\alpha \\
7,03 \times 10^{-1}\end{array}$ & $5,32 \times 10^{-5}$ & $3,12 \times 10^{-4}$ & $6,02 \times 10^{-5}$ & $4,65 \times 10^{-4}$ \\
\hline 4 & $\begin{array}{l}\text { Lantai } 8,00 \mathrm{~m} \text { dan } 13,00 \mathrm{~m} \\
\text { (KLK 04 CR 003) }\end{array}$ & $\begin{array}{l}\beta \\
7,03 \times 10^{-1}\end{array}$ & $4,26 \times 10^{-4}$ & $2,56 \times 10^{-3}$ & $4,87 \times 10^{-4}$ & $4,16 \times 10^{-3}$ \\
\hline \multicolumn{7}{|c|}{ Noble Gas } \\
\hline 1 & $\begin{array}{l}\text { Stack } \\
\text { (KLK } 06 \text { CR 002) }\end{array}$ & $1,85 \times 10^{4}$ & $4,11 \times 10^{3}$ & $6,14 \times 10^{3}$ & $4,89 \times 10^{3}$ & $7,23 \times 10^{3}$ \\
\hline 2 & $\begin{array}{l}\text { Stack } \\
\text { (KLK } 06 \text { CR 001) }\end{array}$ & $1,85 \times 10^{4}$ & $8,17 \times 10^{\circ}$ & $2,48 \times 10^{1}$ & $2,18 \times 10^{1}$ & $4,42 \times 10^{1}$ \\
\hline \multicolumn{7}{|c|}{ Aktivitas Iodine } \\
\hline 1 & $\begin{array}{l}\text { Stack } \\
\text { (KLK } 06 \text { CR004) }\end{array}$ & $8,5 \times 10^{4}$ & - & - & - & - \\
\hline \multicolumn{7}{|c|}{ Tingkat Konsentrasi Radionuklida Gross Beta (Bq/l) } \\
\hline 1 & Lantai $13,00 \mathrm{~m}$ & $7,03 \times 10^{-1}$ & $3,46 \times 10^{-2}$ & $4,24 \times 10^{-2}$ & $3,97 \times 10^{-2}$ & $5,36 \times 10^{-2}$ \\
\hline 2 & Lantai $0,00 \mathrm{~m}$ & $7,03 \times 10^{-1}$ & $2,12 \times 10^{-2}$ & $4,67 \times 10^{-2}$ & $2,48 \times 10^{-2}$ & $5,47 \times 10^{-2}$ \\
\hline
\end{tabular}

Tabel 7 adalah hasil pengukuran parameter operasi sistem proses Reaktor RSG-GAS. Parameter operasi tidak ada yang melanggar batas operasi seperti temperatur maksimum air pendingin $<50^{\circ} \mathrm{C}$. Hal ini dapat dicapai kerena dilakukan pemeliharaan sistem proses secara rutin karena merupakan satu bagian dari kegiatan pengoperasian sistem atau peralatan. Dengan adanya pemeliharaan yang baik maka akan membuat kinerja maupun kemampuan operasi sistem reaktor menjadi semakin baik, efisien dan tahan lama. Pemeliharaan yang dilakukan di reaktor RSG - GAS merupakan suatu kegiatan terprogram dan telah dilaksanakan secara berkala. Dari data hasil kegiatan pemeliharaan katup isolasi terlihat bahwa katup mempunyai kecepatan menutup yang baik yaitu berada dalam rentang waktu 90 100 detik, seperti yang telah ditetapkan dalam Safety Analisis Report (SAR) untuk reaktor RSG-GAS. Dengan kecepatan menutup tersebut diharapkan apabila terjadi gangguan kebocoran air pendingin reaktor pada sistem pemipaan pendingin primer, maka reaktor tidak mengalami kekurangan air sebagai pendingin bahan bakar. Dengan adanya pemeliharaan yang baik, maka frekuensi terjadinya gangguan atau kerusakan menjadi semakin sedikit, sehingga sistem reaktor dapat berfungsi sesuai yang diharapkan. 
Tabel 7. Parameter operasi sistem proses reaktor

\begin{tabular}{|c|c|c|c|c|c|c|c|}
\hline \multirow[b]{2}{*}{ No } & \multirow[b]{2}{*}{ Parameter } & \multirow[b]{2}{*}{ Satuan } & \multirow[b]{2}{*}{ KKS } & \multirow{2}{*}{$\begin{array}{c}\text { Batas } \\
\text { Operasi }\end{array}$} & \multicolumn{2}{|c|}{ Harga Operasi } & \multirow[b]{2}{*}{ Keterangan } \\
\hline & & & & & Min & Maks & \\
\hline $\mathrm{I}$ & Pendingin Primer & & & & & & \\
\hline 1. & Suhu keluar teras & ${ }^{\circ} \mathrm{C}$ & JE01CT001 & $\leq 49,00$ & 25,00 & 41,00 & Normal \\
\hline 2. & Suhu masuk teras & ${ }^{\circ} \mathrm{C}$ & JE01CT811 & $<42,00$ & 25,00 & 37,50 & Normal \\
\hline 3. & Suhu masuk BC02 & ${ }^{\circ} \mathrm{C}$ & JE01CT002 & $\leq 51,00$ & 26,00 & 43,00 & Normal \\
\hline 4. & Suhu keluar BC02 & ${ }^{\circ} \mathrm{C}$ & JE01CT003 & $<42,00$ & 24,50 & 37,50 & Normal \\
\hline 5. & Suhu masuk BC01 & ${ }^{\circ} \mathrm{C}$ & JE01CT004 & $\leq 51,00$ & 26,00 & 43,50 & Normal \\
\hline 6. & Suhu keluar BC01 & ${ }^{\circ} \mathrm{C}$ & JE01CT005 & $<42,00$ & 25,00 & 37,50 & Normal \\
\hline 7. & Suhu masuk teras & ${ }^{\circ} \mathrm{C}$ & JE01CT006 & $<42,00$ & 27,00 & 38,00 & Normal \\
\hline 8. & Laju alir & $\mathrm{m}^{3} / \mathrm{jam}$ & JE01CF811 & $>2902$ & 3150 & 3150 & Normal \\
\hline 9. & Laju alir & $\mathrm{m}^{3} / \mathrm{jam}$ & JE01CF821 & $>2902$ & 3150 & 3150 & Normal \\
\hline 10. & Laju alir & $\mathrm{m}^{3} / \mathrm{jam}$ & JE01CF831 & $>2902$ & 3150 & 3150 & Normal \\
\hline 11. & $\mathrm{pH}$ & - & KBE01CQ02 & $\geq 5,20$ & 5,5 & 6,5 & Normal \\
\hline 12. & Konduktivitas & $\mu \mathrm{S} / \mathrm{cm}$ & KBE01CQ01 & $\leq 8,00$ & 1,19 & 1,34 & Normal \\
\hline II & Pendingin Sekunde & & & & & & \\
\hline 1. & Suhu masuk BC01 & ${ }^{\circ} \mathrm{C}$ & PA01CT001 & $<40,00$ & 27,50 & 37,00 & Normal \\
\hline 2. & Suhu keluar BC01 & ${ }^{\circ} \mathrm{C}$ & РА01СТ002 & $<50,00$ & 26,20 & 39,50 & Normal \\
\hline 3. & Suhu masuk BC02 & ${ }^{\circ} \mathrm{C}$ & РA02СТ001 & $<40,00$ & 26,50 & 36,00 & Normal \\
\hline 4. & Suhu keluar BC02 & ${ }^{\circ} \mathrm{C}$ & РА02СТ002 & $<50,00$ & 26,80 & 40,00 & Normal \\
\hline 5. & Laju alir & $\mathrm{m}^{3} / \mathrm{jam}$ & PA01CF001 & $>1400$ & 1950 & 2050 & Normal \\
\hline 6. & Laju alir & $\mathrm{m}^{3} / \mathrm{jam}$ & PA01CF002 & $>1400$ & 1850 & 2000 & Normal \\
\hline 7. & Laju alir & $\mathrm{m}^{3} / \mathrm{jam}$ & PA02CF001 & $>1400$ & 1850 & 1950 & Normal \\
\hline 8. & Laju alir & $\mathrm{m}^{3} / \mathrm{jam}$ & PA02CF002 & $>1400$ & 1800 & 1900 & Normal \\
\hline 9. & $\begin{array}{l}\text { Level kolam } \\
\text { menara pendingin }\end{array}$ & $\mathrm{m}$ & PA04CL002 & $>4,00$ & 4,17 & 4,50 & Normal \\
\hline 10. & $\begin{array}{l}\text { Level kolam } \\
\text { penyimpan air }\end{array}$ & $\mathrm{m}$ & PA04CL001 & $>1,80$ & 2,10 & 2,35 & Normal \\
\hline 11. & Tek. Isap pompa & bar & PA01CP001 & $>0,10$ & 0,17 & 0,22 & Normal \\
\hline 12. & Tek. Isap pompa & bar & PA02CP001 & $>0,10$ & 0,19 & 0,20 & Normal \\
\hline 13. & Tek. Isap pompa & bar & PA03CP001 & $>0,10$ & 0,19 & 0,22 & Normal \\
\hline 14. & $\mathrm{pH}$ & - & PA01CQ02 & $6,50-8,00$ & 7,33 & 7,85 & Normal \\
\hline 15. & Konduktivitas & $\mu \mathrm{S} / \mathrm{cm}$ & PA01CQ01 & $\leq 1.500$ & 273 & 950 & Normal \\
\hline III & Kolam Reaktor & & & & & & \\
\hline 1. & Kontrol level & $\mathrm{m}$ & JAA01CL001 & $>12,41$ & 12,50 & 12,50 & Normal \\
\hline 2. & Kontrol level & $\mathrm{m}$ & JAA01CL811 & $>12,41$ & 12,44 & 12,52 & Normal \\
\hline 3. & Kontrol level & $\mathrm{m}$ & JAA01CL821 & $>12,41$ & 12,44 & 12,52 & Normal \\
\hline 4. & Kontrol level & $\mathrm{m}$ & JAA01CL831 & $>12,41$ & 12,45 & 12,52 & Normal \\
\hline IV & Kolam Penyimpan B & han Bakar & Bekas & & & & \\
\hline 1. & Kontrol level & $\mathrm{m}$ & JAA02CL001 & $>6,00$ & 6,50 & 6,60 & Normal \\
\hline 2. & Suhu & ${ }^{\circ} \mathrm{C}$ & JAA02СТ001 & $<48,00$ & 24,00 & 36,00 & Normal \\
\hline 3. & Suhu & ${ }^{\circ} \mathrm{C}$ & JAA02CT002 & $<48,00$ & 24,00 & 36,00 & Normal \\
\hline $\mathrm{V}$ & Pemurnian Air Kola & & & & & & \\
\hline 1. & Lajualir & $\mathrm{m}^{3 / \mathrm{jam}}$ & KBE01CF003 & $>20,00$ & 38,00 & 41,50 & Normal \\
\hline 2. & Tekanan & bar & KBE01CP005 & $<1,50$ & 0,30 & 0,45 & Normal \\
\hline 3. & Tekanan & bar & KBE01CP006 & $<2,00$ & 0,05 & 0,70 & Normal \\
\hline VI & Pendingin Kolam & & & & & & \\
\hline 1. & Tekanan & bar & JNA10CP001 & $>0,50$ & 1,10 & 1,90 & Normal \\
\hline 2. & Tekanan & bar & JNA20CP001 & $>0,50$ & 0,80 & 2,20 & Normal \\
\hline 3. & Tekanan & bar & JNA30CP001 & $>0,50$ & 0,90 & 2,90 & Normal \\
\hline VII & Pemurnian Kolam P & yimpan B & han Bakar Bekas & & & & \\
\hline 1. & Lajualir & $\mathrm{m}^{3} / \mathrm{jam}$ & FAK01CF003 & $>8,00$ & 20,00 & 22,00 & Normal \\
\hline 2. & Beda tek. strainer & bar & FAK01CP006 & $<2,00$ & 0,05 & 0,10 & Normal \\
\hline 3. & Suhu masuk $H E$ & ${ }^{\circ} \mathrm{C}$ & FAK01CT001 & $\leq 40,00$ & 23,00 & 38,00 & Normal \\
\hline 4. & Suhu keluar $H E$ & ${ }^{\circ} \mathrm{C}$ & FAK01CT003 & $\leq 37,00$ & 20,00 & 30,00 & Normal \\
\hline
\end{tabular}


Keberhasilan dari kegiatan perawatan dan pemeliharaan sistem pendingin primer JE01, selain didukung oleh pelaksanaan kegiatan pemeliharaan yang telah teratur dengan baik, juga didukung oleh kondisi ruangan dari peralatan tersebut ditempatkan yang selalu terjaga kebersihannya. Karena kondisi tersebut membuat peralatan selalu dalam kondisi yang terjaga bersih dan terpelihara.

Hasil analisis kuantitatif dan kualitatif dari cuplikan sampel air pendingin primer KBE01. Dari hasil pencacahan wadah merineli yang telah terisi sampel air pendingin primer ketika reaktor tidak beroperasi hanya terdeteksi Co-60, dan ini pun bukan aktivitas dari air pendinginnya, akan tetapi dari wadah merinelinya yang telah terkontaminasi. Hal ini dapat terjadi karena sistem pemurnian air pendingin primer bekerja dengan baik sehingga nuklida yang terbentuk pada operasi reaktor sebelumnya, telah habis tertangkap oleh resin penukar ion pada sistem pemurnian air KBE01 dan air pendingin primer telah menjadi bersih dari unsur atau nuklida pengotor. Dari hasil pencacahan wadah merineli yang telah terisi sampel air pendingin primer pada saat reaktor beroperasi tanpa muatan batu topaz, terdeteksi nuklida Mn54 dan Co-60. Mn-54 dengan aktivitas 33,51 Bq/m3 dan kenaikan aktivitas Co-60 yang menjadi 20,02 Bq/ $\mathrm{m}^{3}$ diduga diakibatkan oleh korosi pada pompa, pipa ataupun filter mekanik pada sistem pemurnian air primer. KBE01. Sedangkan dari hasil pencacahan wadah merineli yang telah terisi sampel pada saat reaktor beroperasi dengan muatan batu topaz ada sedikit kenaikan aktivitas Mn-54, yaitu menjadi 43,54 $\mathrm{Bq} / \mathrm{m}^{3}$ dan pada Co-60 menjadi $29,51 \mathrm{~Bq} / \mathrm{m}^{3}$. Kenaikan aktivitas kedua nuklida tersebut diakibatkan oleh sumbangan dari pengotor batu topaz. Akan tetapi kenaikan aktivitas pengotor tersebut masih jauh di bawah nilai ambang batas tingkat baku mutu menurut Peraturan Kepala

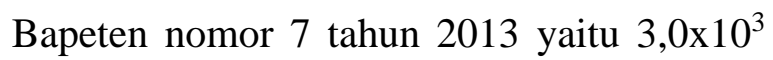
$\mathrm{Bq} / \mathrm{m}^{3}$ belum terlampaui maka reaktor GA. Siwabessy beroperasi dengan aman.

\section{KESIMPULAN}

Hasil penelitian ini menunjukan bahwa konfigurasi teras kerja reaktor RSG-GAS berdaya termal $30 \mathrm{MW}$ namun dioperasikan 15 MW selama satu siklusnya memenuhi

syarat keselamatan operasi dengan menggunakan bahan bakar ${ }^{235} \mathrm{U}$ dengan tingkat muat $250 \mathrm{~g}$ dengan pola manajemen bahan bakar dari dalam keluar. Berdasarkan hasil penelitian kemampuan batang kendali untuk memadamkan reaktor masih handal setelah 30 tahun beroperasi. Kemampuan reaktor menghasilkan fluks neutron termal maksimum di daerah pusat rerata sebesar $2,5 \times 10^{14} \mathrm{n} / \mathrm{cm}^{2} \mathrm{~s}$, margin padam minimum $-3,63 \% \Delta \mathrm{k} / \mathrm{k}$ (stuck rod) dan panjang siklus 42 hari, juga memiliki fasilitas iradiasi rerata 
di dalam teras dengan fluks neutron termal 2,0 x $10^{14} \mathrm{n} / \mathrm{cm}^{2} \mathrm{~s}$. Secara umum reaktor beroperasi dengan aman dan selamat selama 1.042,78 jam dengan energi yang dibangkitkan 640,5971 MWD, scram terjadi sebanyak 13 kali. Belum semua fasilitas iradiasi digunakan secara optimal karena masih sering kosong tidak dimanfaatkan oleh stake holder. Neutron scattering mendominasi utilisasi fasilitas iradiasi dan sebagai pengguna adalah PSTBM. Penggunaan fasilitas iradiasi rabbit system dan fasilitas iradiasi di teras reaktor RSG-GAS perlu ditingkatkan.

\section{UCAPAN TERIMA KASIH}

Kami mengucapkan terima kepada Kepala PRSG yang telah memberikan kesempatan kepada kami untuk melakukan kegiatan ini. Terimakasih juga kepada teman-teman operator dan supervisor atas masukan dan sarannya sehingga membuat tulisan ini jauh lebih bagus dan dapat digunakan untuk mengevaluasi keselamatan operasi reaktor RSG-GAS.

\section{DAFTAR PUSTAKA}

[1]. SETIYANTO DAN TUKIRAN S. Analysis of gamma heating at triga mark reactor core bandung using plate type fuel. Jurnal Tri Dasa Mega. 2016;18(3):127-134.
[2]. MOHAMMAD RAHGOSHAYA, OMID NOORI- KALKHORAN. Calculation of control rod worth and temperature reactivity coefficient of fuel and coolant with burn-up changes for VVRS-2 MWth nuclear reactor. Journal of Nuclear Engineering and Design. 2013; 256:322-331.

[3]. M. VARVAYANNI, N. CATSAROS, M. ANTONOPOULOS-DOMIS. Control rod worth calculations using deterministic and stochastic methods, Annals of Nuclear Energy. 2009;36(1112):1718-1725.

[4]. TERUEL, F.E, RIZWAN-UDDIN. An innovative research reactor design. Journal of Nuclear Engineering and Design. 2009;239(2): 395-407.

[5]. FARHAN MUHAMMAD, ASAD MAJID, Kinetic parameters of a material test research reactor fueled with high density $\mathrm{U}_{3} \mathrm{Si}_{2}$ dispersion fuels. Journal of Progress in Nucl. Energy 2009;51(1):141-145.

[6]. LILY SUPARLINA, Manajemen konversi teras RSG-GAS berbahan bakar silisida tingkat muat tinggi. Jurnal Tri Dasa Mega. 2013; 15 (3):137-149.

[7]. ROKHMADI DAN TUKIRAN S. Efek densitas bahan bakar terhadap parameter koefisien reaktivitas teras RRI. Jurnal Tri Dasa Mega. 2013; 15 (2): 77-89.

[8]. Batan. Laporan Analisis Keselamatan RSG-GAS rev 10.1, 2011. 
[9]. TUKIRAN S, TAGOR MS, SURIAN P. Analisis pengaruh densitas bahan bakar silisida terhadap parameter kinetik teras reaktor RSG-GAS. Jurnal Penelitian Fisika dan Aplikasinya. 2013;3(1):1930.

[10]. IMAN K, TAGOR MS. Desain teras alternatif untuk reaktor riset inovatif (rri) dari aspek neutronik, Jurnal Tri Dasa Mega. 2014;16 (1):110.

[11]. LILY S, TUKIRAN S. Analisis pola manajemen bahan bakar desain teras reaktor riset tipe MTR. Jurnal Tri Dasa Mega. 2014;14(3): 89-99.

[12]. TUKIRAN S, SURIAN P, TAGOR MS, LILY S, JATI S. Desain konseptual teras reaktor riset inovatif berbahan bakar uranium-molibdenum dari aspek neutronik. Jurnal Tri Dasa Mega. 2012;3(14):178-191.

[13]. S. PINEM, TM. SEMBIRING, PH. LEIM. Neutronic and thermal-hydraulic safety analysis for the optimization the Uranium target in the RSG-GAS reactor. Journal of Atom Indonesia.2016; 42(3):123-128.

[14]. T. SURBAKTI AND PURWADI. Karakteristik Reaktivitas Teras Kerja RSG-GAS Selama 30 Tahun Beroperasi. Jurnal Penelitian Fisika dan Aplikasinya (JPFA). 2017; 7(1): 13-26

[15]. SURBAKTI T, PINEM S, AND SUPARLINA L. Dynamic Analysis on the Safety Criteria of the Conceptual Core Design in MTR-type Research Reactor. Journal Atom Indonesia. 2018;44(2):89-98

[16]. LIEM PH, SURBAKTI T, AND DONNY S. Kinetics parameters evaluation on the first core of the RSG GAS (MPR-30) using continuous energy Monte Carlo method. Progress in Nuclear Energy

[17]. PINEM S, LIEM PH, TAGOR MS AND SURBAKTI T. Fuel element burnup measurements for the equilibrium LEU silicide RSG GAS (MPR-30) core under a new fuel management strategy. Annals of Nuclear Energy. 2016;98: 211-217

[18]. TUKIRAN S. AND M. IMRON. Fuel burn-up calculation for RSG-GAS working core. Jurnal Penelitian Fisika dan Aplikasinya. 2017;7(2):89-101 